\title{
How current biologic therapies affect the risk of major adverse cardiovascular events in patients with plaque psoriasis? A systematic review and meta-analysis of randomized controlled trials
}

\author{
Sonia Nartowicz ${ }^{1}$, Ewelina Jakielska1, Monika Priadka1, Zygmunt Adamski', Piotr Ratajczak², Krzysztof Kus ${ }^{2}$ \\ ${ }^{1}$ Department of Dermatology, Poznan University of Medical Sciences, Poznan, Poland \\ ${ }^{2}$ Department of Pharmacoeconomics and Social Pharmacy, Poznan University of Medical Sciences, Poznan, Poland \\ Adv Dermatol Allergol 2020; XXXVII (6): 986-994 \\ DOI: https://doi.org/10.5114/ada.2020.102121
}

\begin{abstract}
Introduction: Concerns have been raised about an increased risk of major adverse cardiovascular events (MACEs) - stroke, myocardial infarction and sudden cardiac death - in patients with plaque psoriasis receiving biologic therapies.

Aim: This review and meta-analysis of randomized controlled trials (RCTs) was to evaluate the risk difference of MACEs between experimental and comparator interventions.

Material and methods: We searched MEDLINE database for suitable trials. Prior to that we identified the search strategy and eligibility criteria. Each RCT was double-blind, placebo controlled and scored five points in Jadad scale. We calculated risk difference (RD) with use of the Mantel-Haenszel fixed-effect method with $95 \%$ confidence intervals (Cls) and calculated i2 statistic to assess heterogeneity. A total of 43 RCTs were included, involving 19,161 patients. Overall, the risk of MACEs in the included studies was $0.1 \%(n=21)$.

Results: There were no statistically significant risk differences in patients treated with biologic therapy vs. placebo $(R D=0.0 ; Z=1.09 ; 95 \% \mathrm{Cl}: 0.0-0.0 ; p=0.28)$; tumour necrosis inhibitors vs. placebo $(R D=0.0 ; Z=0.47 ; 95 \% \mathrm{Cl}$ : $-0.0-0.0 ; p=0.64)$; anti-IL-17A agents vs. placebo $(R D=0.0 ; Z=1.25 ; 95 \% \mathrm{Cl}:-0.0-0.01 ; p=0.21)$; anti-IL-23 agents vs. placebo $(R D=0 ; Z=0.36 ; 95 \% \mathrm{Cl}:-0.0-0.01 ; p=0.72)$; anti-IL-12/23 agents vs. placebo $(R D=0.0 ; Z=0.73$; 95\% Cl: $-0.0-0.0 ; p=0.46)$.

Conclusions: Further trials are needed, including longer follow-up and patients with an increased cardiovascular risk, to assess the risk of MACEs.
\end{abstract}

Key words: psoriasis, biologic therapies, major adverse cardiac events.

\section{Introduction}

Plaque psoriasis is a chronic, genetically determined, non-infectious disease of the skin and joints, affecting approximately 125 million people worldwide [1]. The frequency of psoriasis is related to age, ethnicity and gender, but there are no precise data on the number of patients in total [1]. The inflammation occurs in the skin, but has also an impact on other organs, leading to psoriatic arthritis, Crohn's disease or obesity [2]. It is also associated with an increased risk of cardiovascular events, which are the most common causes of morbidity and mortality in psoriasis [3]. Patients suffering from psoriasis have a higher incidence of cardiovascular diseases: atherosclerosis, arterial hypertension, metabolic syndrome and diabetes [4-8]. The etiopathogenesis of psoriasis and atherosclerosis are connected by serval/several mechanisms such as excessive secretion of vascular endothelial growth factor (VEGF) by cells [9]. Another common process is the formation of inflammatory infiltrates with use of a similar group of cytokines: interleukin-2 (IL-2), IL-6, tumor necrosis factor- $\alpha$ (TNF- $\alpha$ ), interferon $\gamma($ INF- $\gamma$ ) in psoriasis and early atherosclerotic lesions [10]. Major adverse cardiovascular events (MACE) include haemorrhagic and ischemic stroke, myocardial infarction and sudden cardiac death $[11,12]$. The frequency of MACEs in patients with psoriasis is increased, while the potential impact of therapies used in the treatment

Address for correspondence: Sonia Nartowicz, Department of Dermatology, Poznan University of Medical Sciences, 49 Przybyszewskiego St, 60-355 Poznan, Poland, e-mail: sonianartowicz@ymail.com Received: 29.10.2020, accepted: 29.11.2020. 
of psoriasis on the risk of cardiovascular events is unknown [13-15].

Due to the anti-inflammatory effect of the biologic therapies and the similar pathogenesis of psoriasis and atherosclerosis, the influence of these treatments on the cardiovascular risk is being considered [16-19]. The currently used biologics in the treatment of plaque psoriasis are TNF- $\alpha$ inhibitors

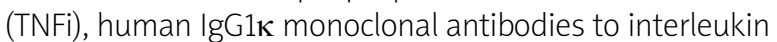
IL-12/23, IL-17 inhibitors and monoclonal antibodies against IL-23. There are several meta-analyses assessing the risk of MACEs occurrence while using biologic therapies during randomized controlled trials (RCTs) in this group of patients [14, 20, 21]. However, described studies did not include the latest classes of biologic therapies, approved by the European Medicines Agency (EMA), such as certolizumab, ixekizumab, or the anti-IL-23 antibody, guselkumab. Therefore, it was necessary to reassess the risk of adverse cardiovascular events in this group of patients. The aim of this review and meta-analysis of RCTs was to show whether there is a statically significant risk of occurrence of the MACEs in patients with plaque psoriasis treated with biologic therapies.

\section{Aims}

The aim of this review and meta-analysis of randomized controlled studies was to show whether there is a significant risk of occurrence of the MACEs in patients with plaque psoriasis treated with biologic therapies.

\section{Material and methods}

\section{Eligibility criteria}

We included 45 randomized, placebo-controlled, double-blind, trials of adults with plaque psoriasis that received a licensed, approved by EMA, dose of biologic therapy compared to placebo, conventional therapy or another licensed dose of the same treatment. Every included trial scored five points in Jadad scale. The study should describe safety outcome data, the number of adverse events, including major adverse cardiovascular events (Figure 1).

\section{Study process and search strategy}

We investigated the Medline database from their inception date to 30 September 2020 to find RCTs describing major adverse cardiovascular events in patients with plaque psoriasis treated with biologic therapies. While searching for suitable abstracts, we did not establish any language restriction, but we applied a filter for randomized controlled trials. The set of used phrases included psoriasis and biologic therapies or the name of the active substance or drug trade name or drug class. Each of the three combinations was used in the process of finding an appropriate abstract. Additionally, we verified the references of the included articles in search of potential new RCTs.
One investigator (S. N.) analysed the entire database searching for suitable articles and simultaneously excluding duplicates. Two investigators (S. N. and E. J.) extracted valuable information and three investigators double-checked included data (S. N., E. J. and M. P.). Other team members (Z. A., P. R., K. K.) were responsible for substantive care, resolving uncertain decisions.

\section{Data extraction and risk of bias assessment}

Each included research was assessed for completeness of the contained information using the Jadad scale. We checked whether the study was randomized and described as double-blind, as well as we overviewed the description of randomization and blinding methods. In addition, we paid attention if the information about the loss of patients from the study, their number and the reason for exclusion (including the safety outcome data) was provided. We extracted data describing study characteristics such as country, study design, length of the randomized controlled phase, number of patients in each research group, information on the active substance used and its doses, use of placebo in the control group, and number of study sites. The patient population designation included age, percentage of females and males, psoriasis area and severity index (PASI) score, percentage of body surface area (BSA) affected by psoriasis and its duration and occurrence of adverse events. We also considered the definition of MACEs used by authors.

The Cochrane Collaboration's tool for assessing the risk of bias was used to evaluate random sequence gen-

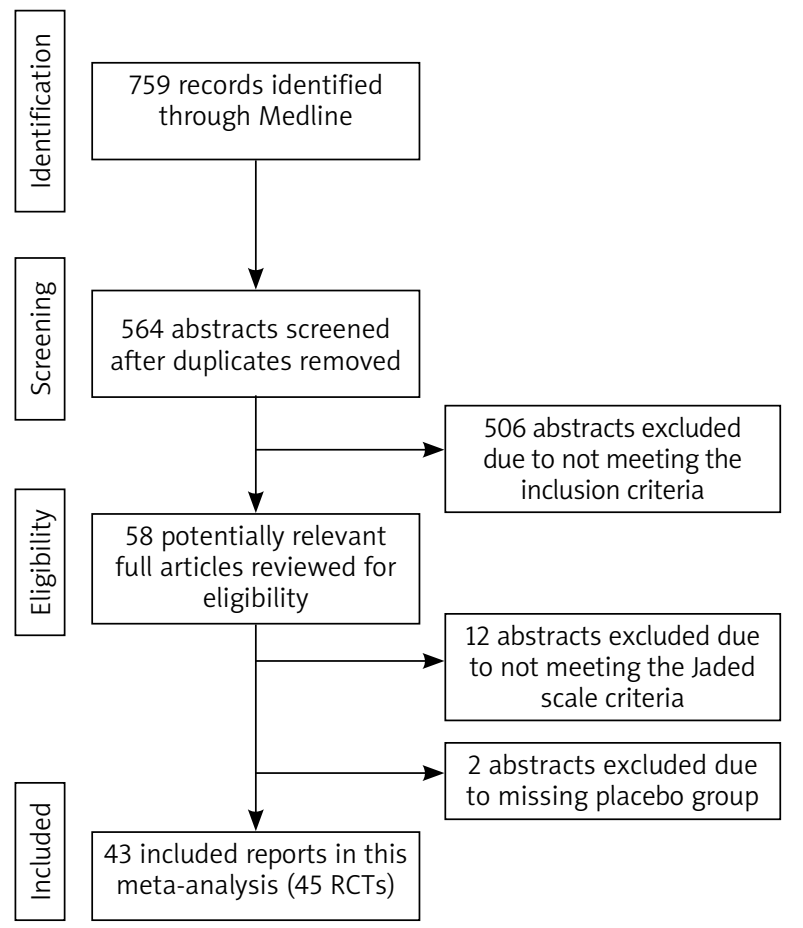

Figure 1. PRISMA 


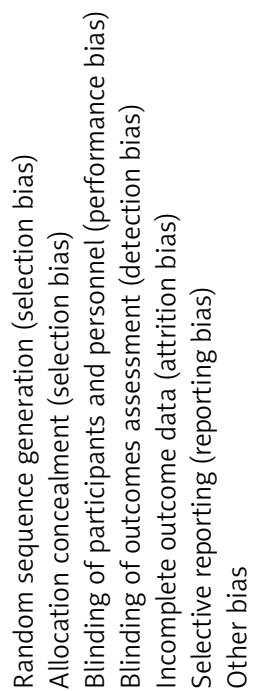

Bachelez et al. 2015

Bagel et al. 2012

Bissonnette et al. 2017

Blauvelt et al. 2015 (FEATURE)

Blauvelt et al. 2017 (JOYAGE-1)

Cai et al. 2016

Chaudhari et al. 2001

Gelfand et al. 2019 (VIP-U)

Gordon et al. 2006

Gordon et al. 2016 (UNCOVER-1)

Gordon et al. 2018 (Ultimma1)

Gordon et al. 2018 (Ultimma2) Gottlieb et al. 2003

Gottlieb et al. 2004

Gottlieb et al. 2011

Gottlieb et al. 2018 (CIMPASI)

Griffiths et al. 2015 (UNCOVER-2)

Griffiths et al. 2015 (UNCOVER-3)

Kerkhof et al. 2008

Langley et al. 2014 (ERASURE)

Langley et al. 2014 (FIXTURE)

Lebwohl et al. 2015 (AMGINE-2)

Lebwohl et al. 2018 (CIMPACT)

Lebwohl et al. 2015 (AMGINE-3)

Leonardi et al. 2003

Leonardi et al. 2008 (PHOENIX1)

Maari et al. 2014

Menter et al. 2008 (EXPRESS-2)

Menter et al. 2008 (REVEAL)

Ohtsuki et al. 2018

Papp et al. 2005

Papp et al. 2008 (PHOENIX2)

Paul et al. 2015 (JUNCTURE)

Reich et al. 2005 (EXPRESS)

Reich et al. 2012

Reich et al. 2016 (LIBERATE)

Reich et al. 2017 (reSURFACE 2)

Reich et al. 2017 (VOYAGE-2)

Saurat et al. 2008 (CHAMPION)

Strober et al. 2011

Tsai et al. 2011 (PEARL)

Tyring et al. 2008

Yang et al. 2012

Figure 2. Risk of bias summary eration, allocation concealment, blinding of participants and personnel, blinding of outcome assessment, incomplete outcome data, selective reporting and other bias. The unclear risk was rated only three times (7\%) in case of incomplete outcome data because studies did not include the reason for participants' exclusion. The total number of excluded patients was 1070 . The most common reason for discontinuation was occurrence of the adverse event ( $n=265 ; 25 \%)$, withdrawal of consent ( $n=195 ; 18 \%)$, unsatisfactory response to treatment ( $n=174 ; 16 \%)$, lost to follow-up ( $n=103 ; 10 \%)$ and other reason $(n=207$; $19 \%)$. Other domains of risk of bias assessment were estimated as a low risk. Funnel plot analysis using the Mantel-Haenszel fixed-effect method was used for assessing potential publication bias. In all extracted comparisons no evidence of publication bias was found (Figures 2, 3).

\section{Data analysis}

The included research data were meta-analysed using Review Manager 5.4. The Mantel-Haenszel type method was used to estimate the risk difference of MACEs in patients receiving biologic therapy versus placebo, assuming a fixed-effects model. A total of 43 RCTs (identified in 38 reports) were included in this meta-analysis as shown in Figure 1 [22-60]. The risk difference (RD) was used because, unlike the Peto OR it does not exclude RCTs without reported MACEs, in both comparisons. Additionally, interpretation of the RD between experimental and comparator interventions is straightforward. The Mantel-Haenszel method is preferable in the Cochrane Handbook for statistical properties with a few events [61]. There were four main comparisons, which included: (1) any biologic therapy (TNFi, anti-IL-17A agents, anti-IL-23 agents, anti-IL12/23 agents) vs. placebo (Figure 4); (2) TNFi (adalimumab, etanercept, infliximab, certolizumab) vs. placebo, anti-IL-17A agents (secukinumab and ixekizumab) vs. placebo; (3) anti-IL-23 agents (guselkumab) vs. placebo; (4) antiIL-12/23 agents (ustekinumab) vs. placebo (Figure 5 ). $\chi^{2}$ test was used to assess significance ( $p$-value $<0.1$ as statistically significant) of heterogeneity between the results of different research and presented it as $R$ test $(R>50 \%$ as significant heterogeneity and $R<25$ as non-significant heterogeneity). The Number Needed to Harm was calculated to provide an alternative way of presenting the statistical results. A funnel plot was used to assess any potential risk of publication bias.

\section{Results}

\section{Study characteristics}

Of the 759 abstracts searched on MEDLINE, only 43 met the inclusion criteria [22-60]. A total of 19,161 patients with plaque psoriasis participated in the included studies. Only of these trials were not multicentre ones [28, 29, 44, 55, 56]. The mean duration of the randomized phase was 14 weeks. Inclusion criteria 


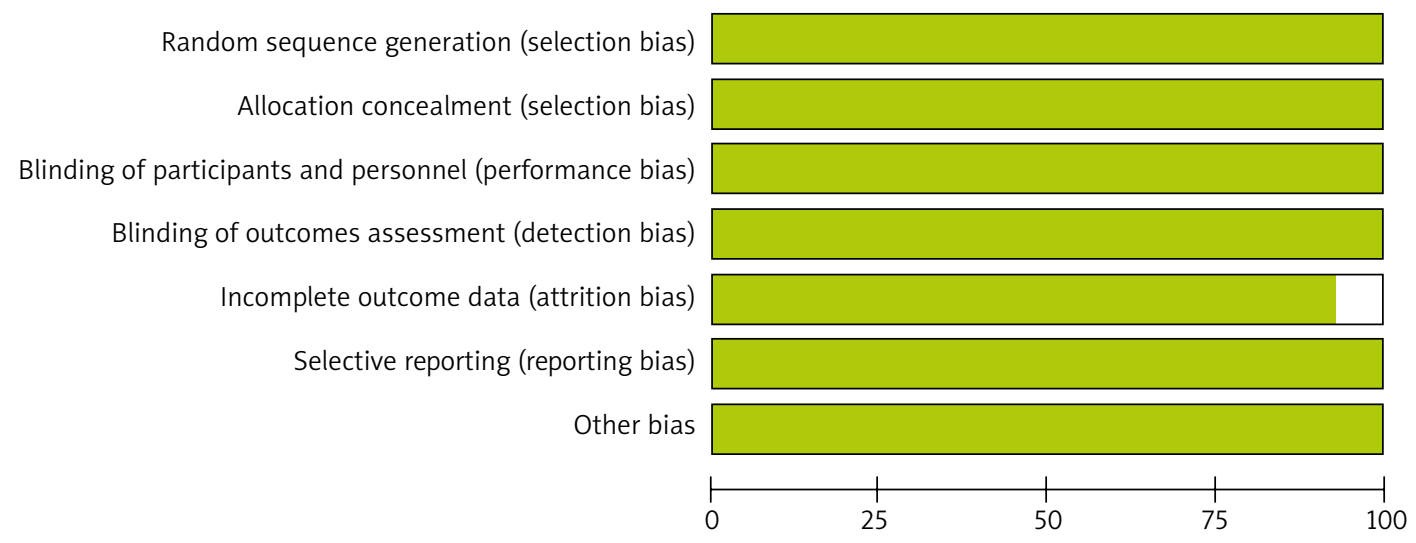

Figure 3. Risk of bias graph

$\square$ Low risk of bias $\square$ Unclear risk of bias $\square$ High risk of bias

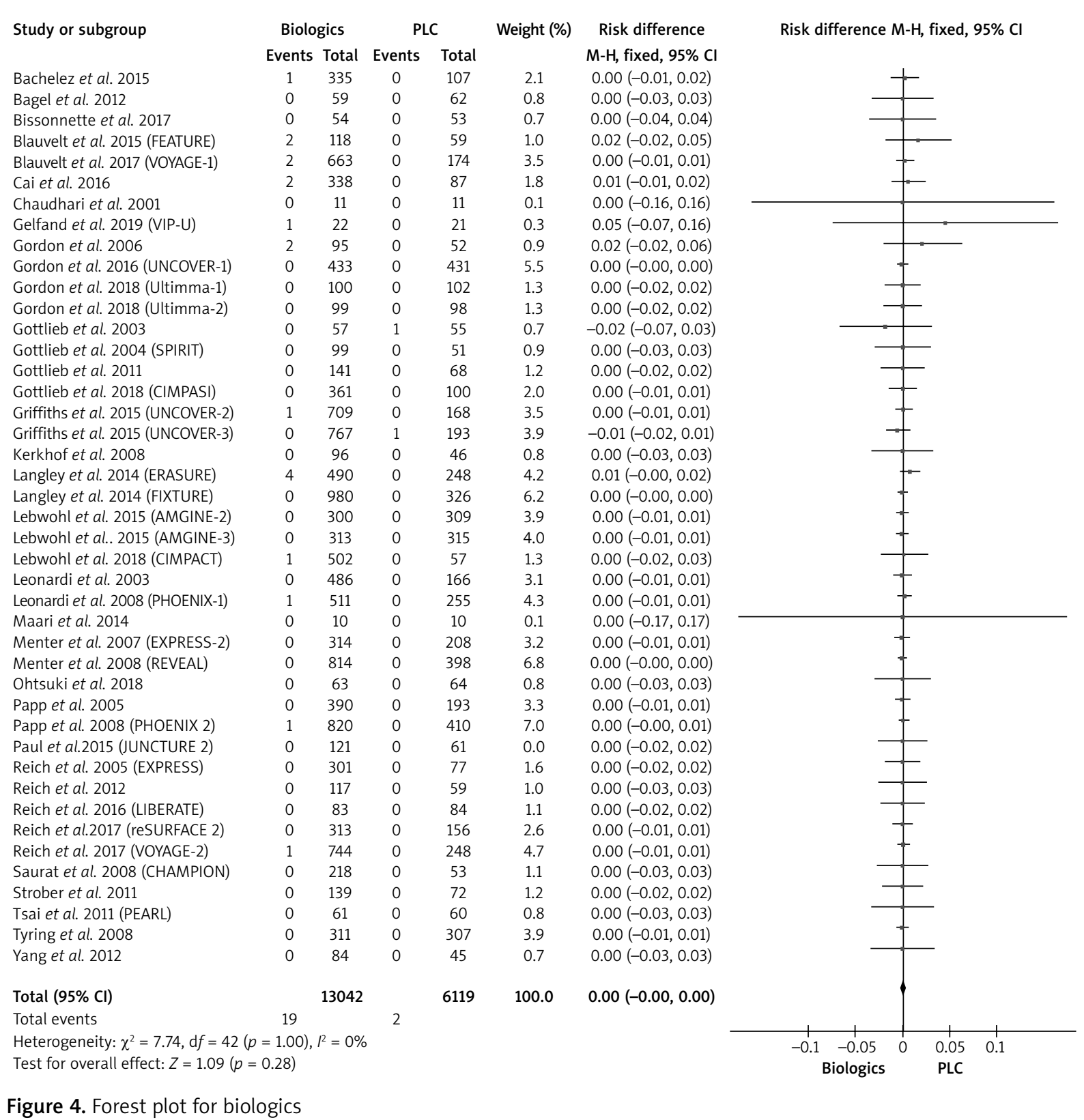


for the RCTs were minimum duration of psoriasis range 6 to 12 months (10 studies did not specify these criteria), minimum BSA range 5-10\% (1 study did not specify these criteria), and PASI range $10-12$ points ( 6 studies did not specify this criterion). Those studies included 20 to 1306 participants, with a male percentage range of $54.35-90.0 \%$, mean age range of $40.1-55.7$ years, mean duration of psoriasis range of 11.9-20.8, and PASI score range of 10.12-28.2.

Overall, the risk of MACEs in the included studies was $0.1 \%(n=21)$, with 2 cases in the control group. Thirtyone trials compared TNFi ( 8 adalimumab, 3 certolizumab,
5 infliximab, 15 etanercept), and eleven MACEs were reported [22-24, 27, 28, 31-40, 43-45, 48, 51, 52, 54-59]. Three RCTs compared the anti-IL-23 agent (guselkumab) with placebo, and there was just one $\operatorname{MACE}[25,47,60]$. Seven trials reported six MACEs, comparing anti-IL-17A agents (secukinumab, ixekizumab) with placebo [31, 37, 39, 50, 61, 62]. Eight RCTs compared ustekinumab versus placebo, and three MACEs were reported [29, 30, 41, 42, $49,53]$. The MACE rates were $0.15 \%$ for TNFi ( 7266 total patients), 0.1\% for anti-IL-23 agents (888 total patients), $0.2 \%$ for anti-IL-17A agents (2552 total patients) and 0.1\% for anti-IL-12/23 agents (2226 total patients) (Figure 5).

\begin{tabular}{|c|c|c|c|c|c|c|c|c|c|c|}
\hline \multirow[t]{2}{*}{ Study or subgroup } & \multicolumn{2}{|c|}{ Anti-IL-23 agents } & \multicolumn{2}{|c|}{ PLC } & \multirow[t]{2}{*}{ Weight (\%) } & \multirow{2}{*}{$\begin{array}{c}\text { Risk difference } \\
\text { M-H, fixed, } 95 \% \mathrm{Cl}\end{array}$} & \multirow{2}{*}{\multicolumn{4}{|c|}{$\begin{array}{c}\text { Risk difference } \\
\text { M-H, fixed, } 95 \% \mathrm{Cl}\end{array}$}} \\
\hline & Events & Total & Events & Total & & & & & & \\
\hline Blauvelt et al. 2017 (VOYAGE-1) & 1 & 329 & 0 & 174 & 36.6 & $0.00(-0.01,0.01)$ & & & & \\
\hline Ohtsuki et al. 2018 & 0 & 63 & 0 & 64 & 10.2 & $0.00(-0.03,0.03)$ & & & & \\
\hline Reich et al. 2017 (VOYAGE-2) & 0 & 496 & 0 & 248 & 53.2 & $0.00(-0.01,0.01)$ & & & & \\
\hline Total $(95 \% \mathrm{Cl})$ & & 888 & & 486 & 100.0 & $0.00(-0.00,0.01)$ & & & & \\
\hline Total events & 1 & 0 & & & & & & & & \\
\hline \multicolumn{7}{|c|}{ Heterogeneity: $\chi^{2}=0.25, \mathrm{~d} f=2(p=0.88), I^{2}=0 \%$} & -0.02 & -0.010 & 0.01 & 0.2 \\
\hline \multicolumn{7}{|c|}{ Test for overall effect: $Z=0.36(p=0.72)$} & Anti-I & L-23 agents & PLC & \\
\hline
\end{tabular}

\begin{tabular}{|c|c|c|c|c|c|c|c|c|}
\hline Study or subgroup & Anti-IL-17 & agents & PL & & Weight (\%) & Risk difference & Risk difference $M$ & $\mathrm{H}$, fixed, $95 \% \mathrm{Cl}$ \\
\hline & Events & Total & Events & Total & & $\mathrm{M}-\mathrm{H}$, fixed, $95 \% \mathrm{Cl}$ & & \\
\hline 1.1.1 Secukinumab & & & & & & & & \\
\hline Blauvelt et al. 2015 (FEATURE) & 2 & 118 & 0 & 59 & 4.3 & $0.02(-0.02,0.05)$ & & \\
\hline Langley et al. 2014 (ERASURE) & 4 & 490 & 0 & 248 & 17.9 & $0.01(-0.00,0.02)$ & & - - \\
\hline Langley et al. 2014 (FIXTURE) & 0 & 654 & 0 & 326 & 23.6 & $0.00(-0.00,0.00)$ & - & \\
\hline Paul et al. 2014 (JUNCTURE) & 0 & 121 & 0 & 61 & 4.4 & $0.00(-0.02,0.02)$ & & \\
\hline Subtotal $(95 \% \mathrm{CI})$ & & 1383 & & 694 & 50.2 & $0.00(-0.00,0.01)$ & & \\
\hline Total events & 6 & & 0 & & & & & \\
\hline Heterogeneity: $\chi^{2}=4.42, \mathrm{~d} f=3$ & $(p=0.22$ & $R^{2}=32 \%$ & & & & & & \\
\hline Test for overall effect: $Z=1.51$ & $p=0.13$ & & & & & & & \\
\hline 1.1.2 Ixekizumab & & & & & & & & \\
\hline Gordon et al. 2016 (UNCOVER-1) & 0 & 433 & 0 & 431 & 23.5 & $0.00(-0.00,0.00)$ & & \\
\hline Griffiths et al. 2015 (UNCOVER-2) & 0 & 351 & 0 & 168 & 12.3 & $0.00(-0.01,0.01)$ & & \\
\hline Griffiths et al. 2015 (UNCOVER-3) & 0 & 385 & 0 & 193 & 14.0 & $0.00(-0.01,0.01)$ & & \\
\hline Subtotal $(95 \% \mathrm{Cl})$ & & 1169 & & 792 & 49.8 & $0.00(-0.00,0.00)$ & & \\
\hline Total events & 0 & & 0 & & & & & \\
\hline Heterogeneity: $\chi^{2}=0.00, \mathrm{~d} f=2$ & $(p=1.00$ & $P^{2}=0 \%$ & & & & & & \\
\hline Test for overall effect: $Z=0.00$ & $(p=1.00)$ & & & & & & & \\
\hline Total $(95 \% \mathrm{Cl})$ & & 2552 & & 1486 & 100.0 & $0.00(-0.00,0.01)$ & & \\
\hline Total events & 6 & & 0 & & & & & \\
\hline Heterogeneity: $\chi^{2}=4.30, \mathrm{~d} f=6$ & $(p=0.64$ & $P^{2}=0 \%$ & & & & & $\begin{array}{lll}-0.02 & -0.01 & 0\end{array}$ & $0.01 \quad 0.2$ \\
\hline $\begin{array}{l}\text { Test for overall effect: } Z=1.25 \text { ( } \\
\text { Test for subgroup differences: } \chi\end{array}$ & $\begin{array}{l}(p=0.21) \\
l^{2}=1.56\end{array}$ & $=1(p=$ & $=0.21)$ & $=35.9 \%$ & & & Anti-IL-17A agents & PLC \\
\hline
\end{tabular}

\begin{tabular}{|c|c|c|c|c|c|c|}
\hline \multirow[t]{2}{*}{ Study or subgroup } & \multicolumn{2}{|c|}{ Ustekinumab } & \multicolumn{2}{|c|}{ PLC } & \multirow[t]{2}{*}{ Weight (\%) } & \multirow{2}{*}{$\begin{array}{l}\text { Risk difference } \\
\text { M-H, fixed, } 95 \% \mathrm{Cl}\end{array}$} \\
\hline & Events & Total & Events & Total & & \\
\hline Gelfand et al. 2019 (VIP-U) & 1 & 22 & 0 & 21 & 1.2 & $0.05(-0.07,0.16)$ \\
\hline Gordon et al. 2018 (Ultimma-1) & 0 & 100 & 0 & 102 & 5.7 & $0.00(-0.02,0.02)$ \\
\hline Gordon et al. 2018 (Ultimma-2) & 0 & 99 & 0 & 98 & 5.5 & $0.00(-0.02,0.02)$ \\
\hline Lebwohl et al. 2015 (AMAGINE-2) & 0 & 300 & 0 & 309 & 17.0 & $0.00(-0.01,0.01)$ \\
\hline Lebwohl et al. 2015 (AMAGINE-3) & 0 & 313 & 0 & 315 & 17.6 & $0.00(-0.01,0.01)$ \\
\hline Leonardi et al. 2008 (PHOENIX-1) & 1 & 511 & 0 & 255 & 19.0 & $0.00(-0.01,0.01)$ \\
\hline Papp et al. 2008 (PHOENIX-2) & 1 & 820 & 0 & 410 & 30.6 & $0.00(-0.00,0.01)$ \\
\hline Tsai et al. 2011 (PEARL) & 0 & 61 & 0 & 60 & 3.4 & $0.00(-0.03,0.03)$ \\
\hline Total $(95 \% \mathrm{Cl})$ & & 2226 & & 1570 & 100.0 & $0.00(-0.00,0.01)$ \\
\hline $\begin{array}{l}\text { Total events } \\
\text { Heterogeneity: } \chi^{2}=0.93, \mathrm{~d} f=7 \\
\text { Test for overall effect: } Z=0.73\end{array}$ & $\begin{array}{c}3 \\
(p=1 . \\
b=0.4\end{array}$ & $P^{2}=0$ & 0 & & & \\
\hline
\end{tabular}

Risk difference $\mathrm{M}-\mathrm{H}$, fixed, $95 \% \mathrm{Cl}$

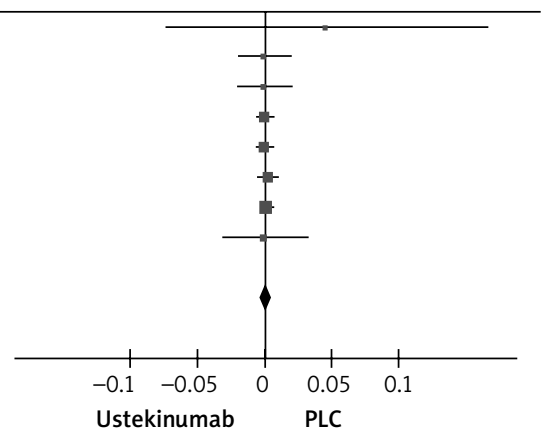

Figure 5. Risk difference (RD) of major adverse cardiovascular events in patients treated with (A) anti-IL-23 agents vs. placebo; (B) anti-IL-17A agents vs. placebo; (C) ustekinumab vs. placebo 
Events Total Events Total

\subsubsection{ADA}

Bissonnette et al. 2017

Blauvelt et al. 2017 (VOYAGE-1)

Cai et al. 2016

Gordon et al. 2006

Maari et al. 2014

Menter et al. 2008 (REVEAL)

Reich et al. 2017 (VOYAGE-2)

Saurat et al. 2008 (CHAMPION)

Subtotal $(95 \% \mathrm{Cl})$

Total events

Heterogeneity: $\chi^{2}=3.12, \mathrm{~d} f=7(p=0.87), p^{2}=0 \%$

Test for overall effect: $Z=1.16(p=0.25)$

\subsubsection{CERTO}

Gottlieb et al. 2018 (CIMPASI)

Lebwohl et al. 2018 (CIMPACT)

Reich et al. 2012

Subtotal $(95 \% \mathrm{Cl})$

Total events

Heterogeneity: $\chi^{2}=0.05, \mathrm{~d} f=2(p=0.98), P^{2}=0 \%$

Test for overall effect: $Z=0.15(p=0.88)$

\subsubsection{INFLIX}

$\begin{array}{ccccc}0 & 361 & 0 & 100 & 3.3 \\ 1 & 332 & 0 & 57 & 2.1 \\ 0 & 117 & 0 & 59 & 1.7 \\ & 810 & & 216 & 7.0 \\ 1 & & 0 & & \end{array}$

$0.00(-0.01,0.01)$

$0.00(-0.02,0.03)$

$0.00(-0.03,0.03)$

$0.00(-0.01,0.01)$

$0.00(-0.04,0.04)$

$0.00(-0.01,0.01)$

$0.01(-0.01,0.02)$

$0.02(-0.02,0.06)$

$0.00(-0.17,0.17)$

$0.00(-0.03,0.0)$

$0.00(-0.00,0.01)$

$0.00(-0.16,0.16)$
$0.00(-0.03,0.03)$
$0.00(-0.01,0.01)$
$0.00(-0.02,0.02)$
$0.00(-0.03,0.03)$
$0.00(-0.01,0.01)$

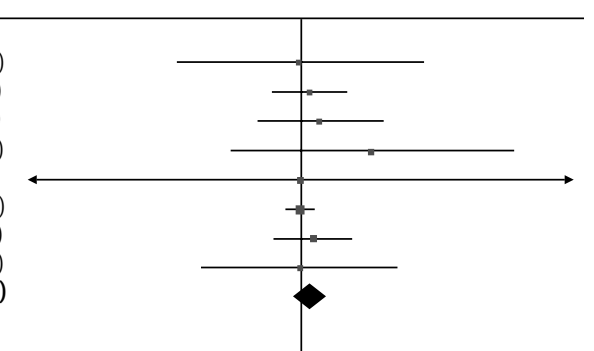

Chaudhari et al. 2001

Gottlieb et al. 2004

Menter et al. 2007 (EXPRESS-2)

Reich et al. 2005 (EXPRESS)

Yang et al. 2012

Subtotal $(95 \% \mathrm{Cl})$

Total events

$\begin{array}{lllll}0 & 11 & 0 & 11 & 0.2\end{array}$

$\begin{array}{lllll}0 & 99 & 0 & 51 & 1.4\end{array}$

$\begin{array}{lllll}0 & 314 & 0 & 208 & 5.3\end{array}$

$\begin{array}{lllll}0 & 301 & 0 & 77 & 2.6\end{array}$

$\begin{array}{lllll}0 & 84 & 0 & 45 & 1.2\end{array}$

$392 \quad 10.8$ $0 \quad 0$

Heterogeneity: $\chi^{2}=0.00, \mathrm{~d} f=4(p=1.00), p^{2}=0 \%$

Test for overall effect: $Z=0.00(p=1.00)$

\subsubsection{ETA}

Bachelez et al. 2015

Bagel et al. 2012

Gottlieb et al. 2003

Gottlieb et al. 2011

Griffiths et al. 2015 (UNCOVER-2)

Griffiths et al. 2015 (UNCOVER-3)

Kerkhof et al. 2008

Langley et al. 2014 (FIXTURE)

Lebwohl et al. 2018 (CIMPACT)

Leonardi et al. 2003

Papp et al. 2005

Reich et al. 2016 (LIBERTE)

Reich et al. 2017 (reSURFACE 2)

Strober et al. 2011

Tyring et al. 2008

Subtotal $(95 \% \mathrm{Cl})$

Total events

Heterogeneity: $\chi^{2}=1.70, \mathrm{~d} f=14(p=1.00), P^{2}=0 \%$

Test for overall effect: $Z=0.27(p=0.78)$

Total $(95 \% \mathrm{Cl})$

7266

3743100.0

Total events

$\begin{array}{cc}1 & 335 \\ 0 & 59 \\ 0 & 57 \\ 0 & 141 \\ 1 & 358 \\ 0 & 382 \\ 0 & 96 \\ 0 & 326 \\ 0 & 170 \\ 0 & 486 \\ 0 & 390 \\ 0 & 83 \\ 0 & 313 \\ 0 & 139 \\ 0 & 311 \\ & 3646\end{array}$

$107 \quad 3.4$

$\begin{array}{ll}62 & 1.3\end{array}$

$55 \quad 1.2$

$\begin{array}{ll}68 & 1.9\end{array}$

$168 \quad 4.8$

$193 \quad 5.4$

$46 \quad 1.3$

$326 \quad 6.9$

$57 \quad 1.8$

$166 \quad 5.2$

$193 \quad 5.5$

$84 \quad 1.8$

$156 \quad 4.4$

$\begin{array}{ll}72 & 2.0\end{array}$

$307 \quad 6.5$

$2060 \quad 53.6$

Heterogeneity: $\chi^{2}=3.78, \mathrm{~d} f=30(p=1.00), P^{2}=0 \%$

Test for overall effect: $Z=0.47(p=0.64)$

Test for subgroup differences: $\chi^{2}=1.24, \mathrm{~d} f=3(p=0.74), I^{2}=0 \%$

$0.00(-0.01,0.02)$

$0.00(-0.03,0.03)$

$-0.02(-0.07,0.03)$

$0.00(-0.02,0.02)$

$0.00(-0.01,0.01)$

$-0.01(-0.02,0.01)$

$0.00(-0.03,0.03)$

$0.00(-0.01,0.01)$

$0.00(-0.03,0.03)$

$0.00(-0.01,0.01)$

$0.00(-0.01,0.01)$

$0.00(-0.02,0.02)$

$0.00(-0.01,0.01)$

$0.00(-0.02,0.02)$

$0.00(-0.01,0.01)$

$-0.00(-0.00,0.00)$
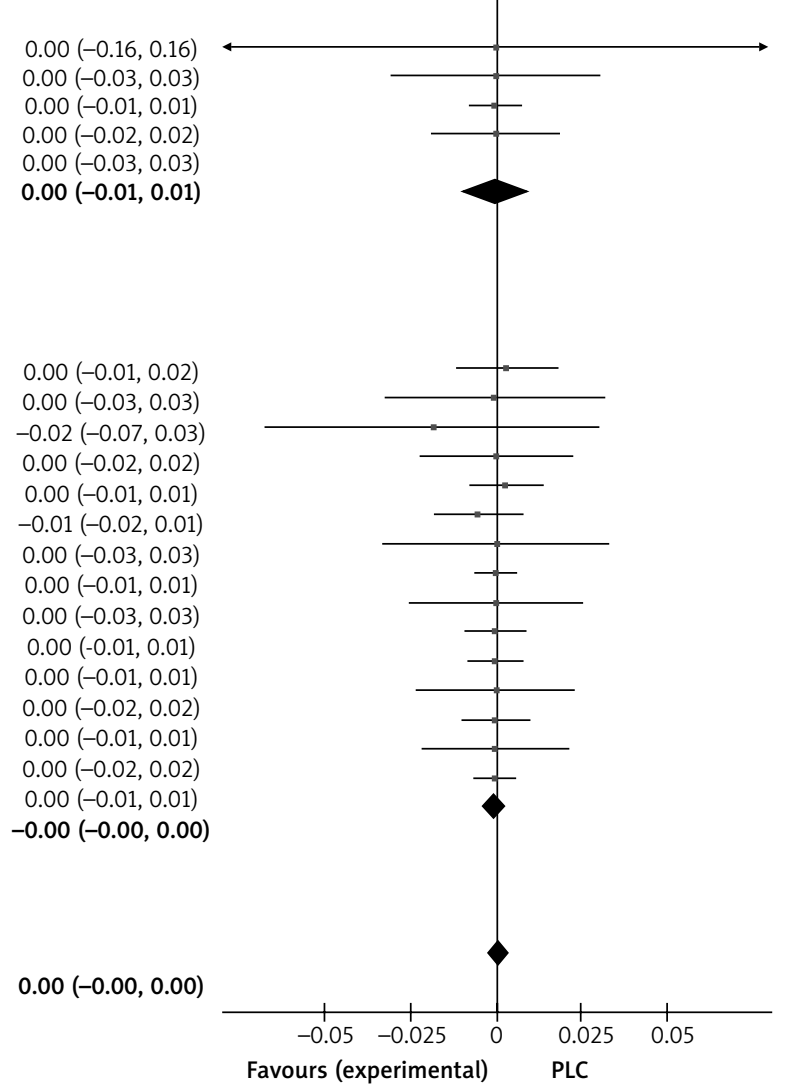

Figure 5. Cont. (D) tumour necrosis factor- $\alpha$ inhibitors (TNFi) vs. placebo. $\mathrm{Cl}$ - confidence interval, $\mathrm{d} f$ - degrees of freedom

\section{Meta-analysis}

From 43 RCTs comparing biologic therapy with placebo only 14 (identified in 13 publications) reported MACEs, the total number of MACEs, during randomized controlled studies, was $21[22,25,27,29,32,35,37,39$, 40, 42, 49, 60, 61] (Figure 4). Analysis including any biologic therapy in comparison to placebo found that there was no statistically significant risk difference of MACES 
occurrence in the treatment group $(R D=0.0 ; Z=1.09$; 95\% Cl: $-0.0-0.0 ; p=0.28$; fixed-effect model). The heterogenicity between included RCTs was rated as low $\left(\chi^{2}=7.74 ; \mathrm{d} f=42 ; p=1.00 ; p^{2}=0 \%\right.$ ) (Figure 4).

Individual analysis has also shown that there was no statistically significant risk difference for patients receiving $T N F i$, including adalimumab, certolizumab, infliximab, etanercept $(R D=0.0 ; Z=0.47 ; 95 \% \mathrm{Cl}$ : -0.0-0.0; $p=0.64$; fixed-effect model) vs. placebo; for anti-IL-23 antibodies - guselkumab (RD =0; $z=0.36$; 95\% Cl: $-0.0-0.01 ; p=0.72$; fixed-effect model) vs. placebo; for anti-IL-17A agents, including secukinumab and ixekizumab $(R D=0.0 ; Z=1.25 ; 95 \% \mathrm{Cl}:-0.0-0.01 ; p=$ 0.21; fixed-effect model) vs. placebo; for anti-IL-12/23 antibodies - ustekinumab $(R D=0.0 ; Z=0.73 ; 95 \% \mathrm{Cl}$ : -0.0 $0.0 ; p=0.46$; fixed-effect model) vs. placebo. The overall heterogenicity of particular analysis was low for TNFi $\left(\chi^{2}=3.78 ; \mathrm{d} f=30 ; p=1.0 ; 1^{2}=0 \%\right) ;$ anti-IL-23 antibodies $\left(\chi^{2}=0.25 ; \mathrm{d} f=2 ; p=0.88 ; \mathrm{i} 2=0 \%\right) ;$ anti-IL-17A antibodies $\left(\chi^{2}=4.30, d f=6 ; p=0.64 ; I^{2}=0 \%\right) ;$ anti-IL-12/23 antibodies $\left(\chi^{2}=0.93, \mathrm{~d} f=7 ; p=1.00 ; p^{2}=0 \%\right.$ ) (Figure 5).

\section{Discussion}

Due to the increasing use of biologic therapies in the treatment of plaque psoriasis and the creation of new medicinal products, it is necessary to assess the risk of adverse events. Complications of biologic treatment depend on the type of used antibodies. Major adverse cardiovascular events are one of the rarest complications but are directly life-threatening. Therefore, in assessing the difference in the risk of MACEs in experimental and comparator interventions, we used a statistical method intended for uncommon events. We found no statistically significant risk difference of MACEs in patients with plaque psoriasis treated with any biologic therapy or placebo in this meta-analysis of RCTs.

The previously performed meta-analysis ambiguously define the risk of MACEs in patients treated with biologic agents. Additionally, they did not include all currently used treatments of plaque psoriasis, approved by EMA. An earlier meta-analysis which included 22 RCTs, reported no association of MACEs between TNFi (adalimumab, etanercept and infliximab) and anti-IL-12/23 agents [14]. This study, like ours, used the Mantel-Haenszel fixed-effect method to assess the risk difference, which is recommended for those type of events [14, 61]. Another meta-analysis has examined patients receiving anti-IL-12/23 agents (ustekinumab and briakinumab), and shown a significant association of the increased risk of MACEs in this group [20]. Authors of this trial also used the Mantel-Haenszel fixed-effect method. The meta-analysis including the biggest number of RCT (38 trials), with use of the Peto's method, found no increased risk of MACEs occurrence between experimental and comparator interventions [21]. The advantage of our study is that it includes all currently used therapies approved for the treat- ment of plaque psoriasis. Contrary to the previous analysis we did not include experimental therapies (as briakinumab), unlicensed doses and did not use the Peto's method which is not recommended for assessing the risk of events such as MACEs. Several limitations should be considered while interpreting this meta-analysis. The search strategy did not include Cochrane or EMBASE. Some of the included trials had a small sample size (the smallest number of study participants was 20). Most of the included trials had a short duration of randomized controlled phase (10-30 weeks). Although we included all currently approved therapies, we did not compare different dosages of the same drugs. Most included trials did not report MACEs separately but compared them with other adverse events. The significant limitation of our metaanalysis is due to lack of information about cardiovascular risk factors, which may have influenced the risk of MACEs independently. Furthermore, the inclusion criteria of the majority of studies practically exclude patients with previously diagnosed cardiovascular diseases. These studies also tend to exclude elderly patients, who have a higher cardiovascular risk (mean age range: 40.1-55.7). It is important to state that in the general population these therapies may be used by patients with cardiovascular risk factors, cardiovascular diseases and other comorbidities or patients of elder age. The risk of MACEs in these groups cannot be assessed based on this meta-analysis and requires further studies.

In conclusion, gathered evidence suggests no significant impact on the risk of MACEs in adult patients with plaque psoriasis over the short term. The limitations of this study such as short duration of the randomized controlled phase or patient characteristics should be regarded. Our recommendations for future studies are to include assessment of cardiovascular risk factors, involve a larger number of patients and extend the time of treatment exposure reflecting the clinical practice for better safety assessment of biologic therapies. Further studies are required to evaluate the impact of biologic therapies on the risk of MACEs in patients with cardiovascular risk factors or cardiovascular comorbidities.

\section{Conclusions}

The risk of MACEs in patients with plaque psoriasis receiving biologic therapies is still undefined. An unknown risk of MACEs is related to the fact that most RCTs have a short randomized controlled phase (1030 weeks), exclude patients with an increased cardiovascular risk and the participants are mainly people under 50 years of age. No statistically significant risk difference in patients treated with any biologic therapy vs. placebo; TNFi vs. placebo; anti-IL-17A agents vs. placebo; anti-12/23 agents vs. placebo; anti-IL-23 agents vs. placebo, has been reported. Further trials are needed, including longer followup and patients with an increased cardiovascular risk, to assess the risk of MACES. 


\section{Conflict of interest}

The authors declare no conflict of interest.

\section{References}

1. Parisi R, Iskandar IYK, Kontopantelis E, et al. National, regional, and worldwide epidemiology of psoriasis: systematic analysis and modelling study. BMJ 2020; 369: m1590.

2. Kaushik SB, Lebwohl MG. Psoriasis: which therapy for which patient: psoriasis comorbidities and preferred systemic agents. J Am Acad Dermatol 2019; 80: 27-40.

3. Lockshin B, Balagula Y, Merola F. Interleukin 17, inflammation, and cardiovascular risk in patients with psoriasis. J Am Acad Dermatol 2018; 79: 345-52.

4. Takeshita J, Grewak S, Langan SM, et al. Psoriasis and comorbid diseases: epidemiology. J Am Acad Dermatol 2017; 76: 377-90.

5. Pietrzak A, Bartosińska J, Chodorowska G, et al. Cardiovascular aspects of psoriasis: an updated review. Int I Dermatol 2013; 52: 153-62.

6. Oliveira M, Rocha B, Duarte G. Psoriasis: classical and emerging comorbidities. An Bras Dermatol 2015; 90: 9-20.

7. Puig L. Cardiometabolic comorbidities in psoriasis and psoriatic arthritis. Int J Mol Sci 2017; 19: 58.

8. Gu WJ, Weng CL, Zhao YT, et al. Psoriasis and risk of cardiovascular disease: a meta-analysis of cohort studies. Int J Cardiol 2013; 168: 4992-6.

9. Armstrong AW, Armstrong EJ, Fuller EN, et al. Smoking and pathogenesis of psoriasis: a review of oxidative, inflammatory and genetic mechanisms. Br J Dermatol 2011; 165: 1162-8.

10. Späh F. Inflammation in atherosclerosis and psoriasis: common pathogenic mechanisms and the potential for an integrated treatment approach. Br J Dermatol 2008; 159: 10-7.

11. Ogdie A, Yu T, Haynes K, et al. Risk of major cardiovascular events in patients with psoriatic arthritis, psoriasis and rheumatoid arthritis: a population-based cohort study. Ann Rheum Dis 2015; 74: 326-32.

12. Armstrong EJ, Harskamp CT, Armstrong AW. Psoriasis and major adverse cardiovascular events: a systematic review and meta analysis of observational studies. J Am Heart Assoc 2013; 2: e000062.

13. Roubille C, Richer V, Starnino T, et al. The effects of tumour necrosis factor inhibitors, methotrexate, non-steroidal antiinflammatory drugs and corticosteroids on cardiovascular events in rheumatoid arthritis, psoriasis and psoriatic arthritis: a systematic review and meta-analysis. Ann Rheum Dis 2015; 74: 480-9.

14. Ryan C, Leonardi CL, Krueger JG, et al. Association between biologic therapies for chronic plaque psoriasis and cardiovascular events: a meta-analysis of randomized controlled trials. JAMA 2011; 306: 864-71.

15. Champs B, Degboé Y, Barnetche T, et al. Short-term risk of major adverse cardiovascular events or congestive heart failure in patients with psoriatic arthritis or psoriasis initiating a biological therapy: a meta-analysis of randomised controlled trials. RMD Open 2019; 5: e000763.

16. Menter A, Griffiths C. Current and future management of psoriasis. Lancet 2007; 370: 272-84.

17. Hansson GK. Inflammation, atherosclerosis, and coronary artery disease. N Engl I Med 2005; 352: 1685-95.

18. Bäck M, Hansson G. Anti-inflammatory therapies for atherosclerosis. Nat Rev Cardiol 2015; 12: 199-211.

19. Elnabawi YA, Oikonomou EK, Dey AK, et al. Association of biologic therapy with coronary inflammation in patients with psoriasis as assessed by perivascular fat attenuation index. JAMA Cardiol 2019; 4: 885-91.

20. Tzellos T, Kyrgidis A, Zouboulis C. Re-evaluation of the risk for major adverse cardiovascular events in patients treated with anti-IL-12/23 biological agents for chronic plaque psoriasis: a meta-analysis of randomized controlled trials. J Eur Acad Dermatol Venereol 2013; 27: 622-7.

21. Rungapiromnan W, Yiu Z, Warren R, et al. Impact of biologic therapies on risk of major adverse cardiovascular events in patients with psoriasis: systematic review and meta analysis of randomized controlled trials. Br J Dermatol 2017; 176: 890-901.

22. Bachelez H, van de Kerkhof PCM, Strohal R, et al. Tofacitinib versus etanercept or placebo in moderate-to-severe chronic plaque psoriasis: a phase 3 randomised non-inferiority trial. Lancet 2015; 386: 552-61.

23. Bagel J, Lynde C, Tyring S, et al. Moderate to severe plaque psoriasis with scalp involvement: a randomized, double-blind, placebo-controlled study of etanercept. J Am Acad Dermatol 2012; 67: 86-92.

24. Bissonnette R, Harel F, Krueger J, et al. TNF-alpha antagonist and vascular inflammation in patients with psoriasis vulgaris: a randomized placebo-controlled study. J Invest Dermatol 2017; 137: 1638-45.

25. Blauvelt B, Papp K, Griffiths C, et al. Efficacy and safety of guselkumab, an anti-interleukin-23 monoclonal antibody, compared with adalimumab for the continuous treatment of patients with moderate to severe psoriasis: results from the phase III, double-blinded, placebo- and active comparator-controlled VOYAGE 1 trial. J Am Acad Dermatol 2017; 76: 405-17.

26. Blauvelt A, Reich K, Tsai TF, et al. Secukinumab is superior to ustekinumab in clearing skin of subjects with moderate-tosevere plaque psoriasis up to 1 year: results from the CLEAR study. J Am Acad Dermatol 2017; 76: 60-9.e9.

27. Cai L, Gu J, Zheng J, et al. Efficacy and safety of adalimumab in Chinese patients with moderate-to-severe plaque psoriasis: results from a phase 3, randomized, placebo-controlled, double-blind study. J Eur Acad Dermatol Venereol 2017; 31: 89-95.

28. Chaudhari U, Romano P, Mulcahy L, et al. Efficacy and safety of infliximab monotherapy for plaque-type psoriasis: a randomised trial. Lancet 2001; 357: 1842-7.

29. Gelfand JM Shin DB, Alavi A, et al. A phase iv, randomized, double-blind, placebo-controlled crossover study of the effects of ustekinumab on vascular inflammation in psoriasis (the VIP-U Trial). J Invest Dermatol 2020; 140: 85-93.e2.

30. Gordon KB, Strober B, Lebwohl M, et al. Efficacy and safety of risankizumab in moderate-to-severe plaque psoriasis (UItIMMa-1 and UItIMMa-2): results from two double-blind, randomised, placebo-controlled and ustekinumab-controlled phase 3 trials. Lancet 2018; 392: 650-61.

31. Gordon KB, Blauvelt A, Papp K, et al. Phase 3 trials of ixekizumab in moderate-to-severe plaque psoriasis. N Engl J Med 2016; 375: 345-56.

32. Gordon KB, Langley R, Leonradi C, et al. Clinical response to adalimumab treatment in patients with moderate to severe psoriasis: double-blind, randomized controlled trial and openlabel extension study. J Am Acad Dermatol 2006; 55: 598-606.

33. Gottlieb AB, Blauvelt A, Thaci D, et al. Certolizumab pegol for the treatment of chronic plaque psoriasis: results through 48 weeks from 2 phase 3, multicenter, randomized, double-blinded, placebo-controlled studies (CIMPASI-1 and CIMPASI-2). J Am Acad Dermatol 2018; 79: 302-14.e6. 
34. Gottlieb AB, Leonardi C, Kerdel F, et al. Efficacy and safety of briakinumab vs. etanercept and placebo in patients with moderate to severe chronic plaque psoriasis: briakinumab vs. etanercept for psoriasis treatment. Br J Dermatol 2011; 165: 652-60.

35. Gottlieb AB, Matheson RT, Lowe N, et al. A randomized trial of etanercept as monotherapy for psoriasis. Arch Dermatol 2003; 139: 1627-32.

36. Gottlieb AB, Evans R, Li S, et al. Infliximab induction therapy for patients with severe plaque-type psoriasis: a randomized double-blind, placebo-controlled trial. J Am Acad Dermatol 2004; 51: 534-42.

37. Griffiths C, Reich K, Lebwohl M, et al. Comparison of ixekizumab with etanercept or placebo in moderate-to-severe psoriasis (UNCOVER-2 and UNCOVER-3): results from two phase 3 randomised trials. Lancet 2015; 386: 541-51.

38. van de Kerkhof PC, Segaert S, Lahfa M, et al. Once weekly administration of etanercept $50 \mathrm{mg}$ is efficacious and well tolerated in patients with moderate-to-severe plaque psoriasis: a randomized controlled trial with open-label extension. $\mathrm{Br}$ J Dermatol 2008; 159: 1177-85.

39. Langley RG, Elewski B, Lebwohl M, et al. Secukinumab in plaque psoriasis - results of two phase 3 trials. N Engl J Med 2014; 371: 326-38.

40. Lebwohl M, Blauvelt A, Paul C, et al. Certolizumab pegol for the treatment of chronic plaque psoriasis: results through 48 weeks of a phase 3 , multicenter, randomized, double-blind, etanercept- and placebo-controlled study (CIMPACT). J Am Acad Dermatol 2018; 79: 266-76.e5.

41. Lebwohl M, Strober B, Menter A, et al. Phase 3 studies comparing brodalumab with ustekinumab in psoriasis. N Engl Med 2015; 373: 1318-28.

42. Leonardi CL, Kimball AB, Papp KA, et al. Efficacy and safety of ustekinumab, a human interleukin-12/23 monoclonal antibody, in patients with psoriasis: 76-week results from a randomised, double-blind, placebo-controlled trial (PHOENIX 1). Lancet 2008; 371: 1665-74.

43. Leonardi CL, Powers JL, Matheson RT, et al. Etanercept as monotherapy in patients with psoriasis. N Engl J Med 2003; 349: 2014-22.

44. Maari C, Bolduc C, Nigen S, et al. Effect of adalimumab on sleep parameters in patients with psoriasis and obstructive sleep apnea: a randomized controlled trial. J Dermatol Treat 2014; 25: 7-60.

45. Menter A, Feldman SR, Weinstein GD, et al. A randomized comparison of continuous vs. intermittent infliximab maintenance regimens over 1 year in the treatment of moderateto-severe plaque psoriasis. I Am Acad Dermatol 2007; 56: 31.e1-15.

46. Menter A, Tyring S, Gordon K, et al. Adalimumab therapy for moderate to severe psoriasis: a randomized, controlled phase III trial. J Am Acad Dermatol 2008; 58: 106-15.

47. Ohtsuki M, Kubo H, Morishima H, et al. Guselkumab, an anti-interleukin-23 monoclonal antibody, for the treatment of moderate to severe plaque-type psoriasis in Japanese patients: Efficacy and safety results from a phase 3, randomized, double-blind, placebo-controlled study. J Dermatol 2018; 45: 1053-62.

48. Papp K, Tyring S, Prinz J, et al. A global phase III randomized controlled trial of etanercept in psoriasis: safety, efficacy, and effect of dose reduction. Br J Dermatol 2005; 152: 1304-12.

49. Papp K, Langley R, Lebwohl M, et al. Efficacy and safety of ustekinumab, a human interleukin-12/23 monoclonal antibody, in patients with psoriasis: 52-week results from a ran- domised, double-blind, placebo-controlled trial (PHOENIX 2). Lancet 2008; 371: 1675-84.

50. Paul C, Lacour JP, Tedremets L, et al. Efficacy, safety and usability of secukinumab administration by autoinjector/pen in psoriasis: a randomized, controlled trial (JUNCTURE). J Eur Acad Dermatol Venereol 2015; 29: 1082-90.

51. Hai-zhen Y, Ke W, Hong-zhong J, et al. Infliximab monotherapy for Chinese patients with moderate to severe plaque psoriasis: a randomized, double-blind, placebo-controlled multicenter trial. Chin Med J 2012; 125: 1845-7.

52. Tyring S, Gottlieb A, Papp K, et al. Etanercept and clinical outcomes, fatigue, and depression in psoriasis: double-blind placebo-controlled randomised phase III trial. Lancet 2006; 367: 29-35.

53. Tsai TF, Ho JC, Song M, et al. Efficacy and safety of ustekinum$a b$ for the treatment of moderate-to-severe psoriasis: a phase III, randomized, placebo-controlled trial in Taiwanese and Korean patients (PEARL). J Dermatol Sci 2011; 63: 154-63.

54. Strober BE, Crowley JJ, Yamauchi PS, et al. Efficacy and safety results from a phase III, randomized controlled trial comparing the safety and efficacy of briakinumab with etanercept and placebo in patients with moderate to severe chronic plaque psoriasis: briakinumab vs. etanercept for psoriasis treatment. Br J Dermatol 2011; 165: 661-8.

55. Saurat JH, Stingl G, Duberter L, et al. Efficacy and safety results from the randomized controlled comparative study of adalimumab vs. methotrexate vs. placebo in patients with psoriasis (CHAMPION). Br J Dermatol 2008; 158: 558-66.

56. Reich K, Ortonne JP, Gottlieb AB, et al. Successful treatment of moderate to severe plaque psoriasis with the PEGylated Fab certolizumab pegol: results of a phase II randomized, placebocontrolled trial with a re-treatment extension: efficacy and safety of certolizumab pegol in plaque psoriasis. Br J Dermatol 2012; 167: 180-90

57. Reich K, Nestle F, Papp K, et al. Infliximab induction and maintenance therapy for moderate-to-severe psoriasis: a phase III, multicentre, double-blind trial. Lancet 2015; 366: 1367-74.

58. Reich K, Papp K, Blauvelt A, et al. Tildrakizumab versus placebo or etanercept for chronic plaque psoriasis (reSURFACE 1 and reSURFACE 2): results from two randomised controlled, phase 3 trials. Lancet 2017; 390: 276-88.

59. Reich K, Gooderham M, Bewley A, et al. The efficacy and safety of apremilast, etanercept and placebo in patients with moderate-to-severe plaque psoriasis: 52-week results from a phase IIIb, randomized, placebo-controlled trial (LIBERATE). J Eur Acad Dermatol Venereol 2017; 31: 507-17.

60. Reich K, Armstrong W, Foley P, et al. Efficacy and safety of guselkumab, an anti-interleukin-23 monoclonal antibody, compared with adalimumab for the treatment of patients with moderate to severe psoriasis with randomized withdrawal and retreatment: results from the phase III, doubleblind, placebo- and active comparator-controlled VOYAGE 2 trial. J Am Acad Dermatol 2017; 76: 418-31.

61. Deeks JJ, Higgins JPT, Altman DG. Chapter 10: Analysing data and undertaking meta-analyses. In: Cochrane Handbook for Systematic Reviews of Interventions version 6.1. J Higgins, J Thomas (eds). The Cochrane Collaboration 2020.

62. Blauvelt A, Prinz JC, Gottlieb AB, et al. Secukinumab administration by pre-filled syringe: efficacy, safety and usability results from a randomized controlled trial in psoriasis (FEATURE). Br J Dermatol 2015; 172: 484-93. 